\title{
An Analysis of the Impact of Dual Crises on Hong Kong's Financial Development
}

\author{
Keyi Wang* \\ Beijing Forestry University, Beijing, 100083, China
}

\section{ARTICLE INFO}

Article history

Received: 1 June 2021

Revised: 10 June 2021

Accepted: 20 October 2021

Published Online: 30 October 2021

\section{Keywords:}

Hong Kong

Marginalized

International financial center

\section{Introduction}

According to the Global Financial Center Index (GFCI), the world's leading financial centers ranked London, New York, Hong Kong, Singapore, Tokyo and Shanghai in 2018. However, GFCI in 2020 showed that the order is New York, London, Tokyo, Shanghai, Singapore, Hong Kong and Beijing. In just two years, Hong Kong has lost its position as the world's three major financial centers, and has gradually lost its competitive advantage and strength. We have witnessed Hong Kong's international ranking fall out of the high circle, moving back, which indicates that Hong Kong will gradually be marginalized.

However, in my opinion, it is not accurate to talk about Hong Kong's marginalization at this time, and its marginalization lacks a scope to define where the margin is. What is the first definition of marginalization? Marginalization is to point to the development of people or things in the opposite direction of movement and change. Marginalization is actually a more abstract statement, in short, is non-central, non-mainstream, or by the mainstream (mainstream society, mainstream people, mainstream ideology, mainstream culture, mainstream economy, etc.) excluded, not inclusive. The

\begin{abstract}
According to the GFCI ranking from 2018-2020, Hong Kong fell from third to sixth, surpassing cities in other Asian countries and some inland cities in China. Hong Kong's marginalization has intensified because of the impact of the new crown epidemic and anti-repair incidents. However, Hong Kong's marginalization is indeed somewhat inappropriate. As far as the situation is concerned, Hong Kong still has a strong competitiveness, although it is lagging behind, but Hong Kong should think deeply about the strategy and system of "one country, two systems", believe in the country's strategic intention and adjust its state in time to re-exclude the public's understanding of its marginalization.
\end{abstract}

simple explanation is that from the center and the mainstream is gradually removed to the non-center, non-mainstream.And for Hong Kong, what is central and mainstream relative to its marginalization? It is true that Hong Kong has been lagging behind in recent years because of successive problems, but it is still high, ahead of the vast majority of the world's cities. Hong Kong is definitely in the upper circle, not on the edge. If the scope is divided into the world's three major financial centers, there is no doubt that Hong Kong has been eliminated from this circle and has already exceeded the margin. But if the scope is divided into the top ten financial centers in the world, it can be said that Hong Kong is gradually marginalized. From this point of view, compared with marginalization, what is the so-called center, what is the mainstream, and what has led to the marginalization of Hong Kong in a certain range?

\section{The Impact of the Dual Crisis on Hong Kong's Finance}

\subsection{Section Counter-Examinations}

Since June 2019, some Hong Kong reactionaries and radical forces have carried out various radical protests in the name of peaceful marches and rallies. Although the HKSAR Government has repeatedly stated that

*Corresponding Author:

Keyi Wang,

Beijing Forestry University, Beijing, 100083, China;

Email:1264164288@qq.com 
the revision of the Fugitive Offenders Ordinance has been completely discontinued, they continue to use the guise of" counter-examinations" as a pretext for further escalation, escalating violence and increasing social outreach. The march, which began in June, has repeatedly turned violent, and its actions go well beyond peaceful demonstrations ${ }^{[1]}$. All kinds of strike movement appeared, the major Hong Kong railway hubs were paralyzed, most road traffic was blocked, at the same time, local shops, restaurants and retail in Hong Kong were affected, and even forced to close, leading to the damage of people's livelihood economy.

\subsection{New Crown Epidemic}

Hong Kong's turmoil not only has an impact on the normal life of the local people, but also makes Hong Kong's economic development into an unprecedented downturn. Hong Kong's economy has fallen sharply since the outbreak of the anti-regime storm, and the subsequent outbreak of the new crown epidemic has hit Hong Kong's finance even more seriously. According to the data, Hong Kong's GDP fell 2.9 percent in the third quarter of 2019 , the first negative growth in a decade ${ }^{[2]}$. Several violent anti-government demonstrations, a series of violent confrontations, and the rapid spread of Internet information, across the country, even the world's travelers, lead to a more serious situation. As a pillar industry in Hong Kong, the development of tourism also entered the cold winter. November 2019, Hong Kong visitors fell $55.9 \%$ year on year. Among them the number of mainland tourists fell 58.4 percent. The negative development of tourism has severely hit the retail sector in Hong Kong. Meanwhile, the opening of Hainan duty-free shops has also deprived Hong Kong duty-free shops and the purchasing industry of certain advantages. As a result of a $25.4 \%$ year-on-year decline in retail sales in Mainland. It fell 25.3 per cent in November. In 2020, due to the full outbreak of the new crown, Hong Kong's economy has suffered a double blow. In the first quarter of 2020, Hong Kong GDP fell $8.9 \%$ year on year, private consumption fell 10.1 per cent, investment declined by 14.3 per cent, and GDP fell by more than 6 per cent in the second quarter ${ }^{[3]}$.

\section{3. "Marginalized" Hong Kong}

\subsection{Two Aspects}

Compared with the top three financial centers in the world, Hong Kong has gradually lost its competitive advantage and position and gradually marginalized. From 2018 to 2020, Hong Kong's ranking in international financial centers fell from third to sixth, surpassing Singapore, Shanghai and Tokyo, and catching up with
Beijing in 2018 after Hong Kong in the top 10. Hong Kong's marginalization of these cities can be divided into two aspects.

\subsection{From Domestic Point of View}

From the domestic point of view, Hong Kong's current advantages and resources in the motherland are gradually divided, Shanghai, Shenzhen, Beijing, Hainan and other places of finance with the support of the Chinese government gradually developed, including Shanghai, Beijing, Shenzhen has entered the world's top ten financial centers ${ }^{[4]}$. Compared with Hong Kong, Shanghai has the same superior geographical location. Shanghai is located in the Yangtze River Delta economic belt. It has the advantages of natural regional time zone and economic hinterland, which constitutes the centripetal force of becoming a financial center. At the same time, this geographical location is located in the West Bank of the Pacific, facing the North American Free Trade Zone, China's new gathering center - land transportation, shipping, air transportation center and international trade center and financial center ${ }^{[3]}$. In Hong Kong, the same superior geographical location, located in the Pearl River Delta, in the Pearl River estuary, has a good transshipment advantage, has a large and superior port, the same shipping and air transport, and Southeast Asian countries can also be closely linked. But Shenzhen also has the same geographical advantage, only Beijing is located inland, so Hong Kong's trade geographical advantage is not unique and irreplaceable. At the same time, Shanghai is the biggest threat to Hong Kong's international financial position. Despite the traditional advantages of the global financial market, Shanghai ranks the ranking of second only to the New York, London, Hong Kong, Singapore and other old asset management centers in the latest 29th index report, with its obvious advantages. Moreover, another highlight of Shanghai 's greatest financial potential is financial technology. In the 28th index, Shanghai ranks third in the field of financial technology, while the 29th issue is more advanced, second only to New York. Shanghai's ability to allocate global resources is increasing, and an excellent global asset management center is taking shape. As for Shenzhen, its special geographical location, special opportunities and special opportunities have created Shenzhen's financial development almost simultaneously with manufacturing and commerce. Shenzhen back to Hong Kong, which makes many Hong Kong financial business has its radiation effect, and gradually with the development of the financial industry in part of Hong Kong, and Shenzhen less restrictions than Hong Kong, and more countries and inland enterprise support, and have more land and opportunities to let new foreign enterprises, these absolute advantages are not many 
financial centers, which make Shenzhen develop rapidly in such a short time. Compared with these cities, especially Shanghai, Hong Kong, on the one hand, is in a relatively deformed historical fact compared with the prosperity of the inland, relying on the closed and poor cities of Mainland year. More than a hundred years ago, Hong Kong became a British colony, first exposed to industrial civilization and assumed the function of British trade transit to China, thus enabling Hong Kong to develop rapidly from a small fishing village to a trading port, but even then Hong Kong failed to surpass Shanghai. But until China's relationship with the Soviet Union grew colder, and China's access to resources from the Soviet Union became narrower, but this development of socialism still required access to resources and technology like the West, so Hong Kong became a good medium and the only bridge between China and the West. At that time, Hong Kong, backed by a huge market like Chinese mainland, reached out to the world and became an Asia-Pacific and even an international financial center, which explained why other cities in Asia, such as Singapore, could not surpass Hong Kong as an Asian financial center, Its other conditions are no less than Hong Kong, but lack the support of a huge market like China. However, over time, the reason for Hong Kong's prosperity has also become the reason why Hong Kong was gradually overtaken by mainland cities. At that time, Hong Kong's rise was caused by the inconvenience of China's foreign exchange and trade. This was a temporary situation. Over time, the inconvenience gradually disappeared and the Chinese market became more open, which made Hong Kong no longer the only foreign window of China. China's market was gradually divided by several other cities and the rampant independence of Hong Kong. This led to the continuous deterioration of Hong Kong's social situation, which far exceeded the inherent scope and bottom line of "one country, two systems ". It is clearly not a good decision for China to spend all its resources on Hong Kong. As a result, without China's power support, Hong Kong's gradual transcendence in Mainland region is only the result of time.

\subsection{From International Point of View}

At the international level, although New York, London and Hong Kong were once known as the three largest financial centers in the world, there is still a certain gap between Hong Kong and New York and London in terms of real strength. Whether it is international financial resource allocation capacity or the scope of financial services, there is still a barrier to the depth, breadth and quality of global financial markets ${ }^{[6]}$. This is not just against Hong Kong, New York and London and other international financial centers other than themselves, so it is beyond doubt that Hong Kong can be ranked third and disguised first. Moreover, in recent years, the focus of the global economy has shown an important feature of a tilt to emerging economies. Their contribution to world economic development has been steadily improved and has become an important force in promoting world economic development. Judging from the basic logic of the change of global economic and financial centers, the growth of economic strength usually requires a matching financial strength, and financial technology will become an important driving force of the pattern change. The development of financial technology affects the connotation and form of the future international financial center. According to the Global Financial Technology Centre Alliance, London, Singapore, New York, Shanghai and Tokyo are also at the forefront in global financial technology development, while Hong Kong lags slightly behind its financial technology level compared with these countries ${ }^{[7]}$. Therefore, I think the international marginalization is still a difficult reason for Hong Kong's own development. Hong Kong's loss of full support from the Chinese market, coupled with other factors such as counter-examinations and the new crown epidemic, has overtaken Tokyo with Japan's equally non-China market economy and resources. Geography is also lost but is overtaken by Singapore, which has been suppressed for years without a strong market like China.

\section{4. "Not Marginalized" Hong Kong}

From 2018 to 2020, it is true that Hong Kong did break away from the high circle of competition during this period, seemingly "marginalized" by the high circle of Hong Kong. In fact, the data are still extremely considerable, still far behind other financial centers, never marginalized. At the same time, according to the latest 2021 international financial center ranking, Hong Kong returned to fourth place, Shanghai is still squeezed into the top three, although Shanghai still squeezed Hong Kong out of the top three. But from the overall score, Hong Kong is only one point behind Shanghai, so Hong Kong's strength is still not to be underestimated. There is still a strong recovery and competitiveness.

Only a year later will Hong Kong recover from the riots and the new crown epidemic less than a year later, and its financial markets will show strong resilience and resilience, not only maintaining the stability of the financial system. And continue to play the role of international financial center market financing.

First of all, according to Hong Kong's own conditions, one country, two systems give Hong Kong an excellent intermediary identity. It is difficult to find any system like Hong Kong that can accommodate two systems as a meeting 
point and buffer zone for Chinese and Western capital.

At the same time, it is impossible for Hong Kong to build one of the world's top international financial centers for so many years without a certain historical precipitation and reserve force. At the same time, the cost of building one of the world's top international financial centers is absolutely not low. These costs are not only reflected in the precipitation of time, but also in a series of legal systems, stock market system, foreign exchange control, tax system, resource allocation, customer source, capital investment and so on, which are difficult to estimate, and Hong Kong has experienced so many years of practice, also created their own unique financial system, image, similar to the historical heritage of the rich family, even if the impact, its status can not be shaken by the latecomers.

Hong Kong has survived successive crises in history. The resilience of its financial markets is unquestionable. Whether in the Asian financial crisis or otherwise, Hong Kong can survive without danger. As you can see, Hong Kong's financial markets as a whole are stable and orderly, the sub-markets run steadily, and market elasticity and toughness are more prominent. So in response to recent crises, Hong Kong in 2020 took a series of measures to deal with it. In the money market, Hong Kong as a whole maintains a low interest rate environment in 2020, making the short-term interest rate run low, more liquid. The overnight interbank lending rate for Hong Kong dollars fell further to 0.04 per cent at the end of the year. On the exchange market, the Hong Kong exchange rate linkage mechanism operates in an orderly manner, making the Hong Kong dollar as a whole stable. The Hong Kong dollar has remained close to HK $\$ 7.75$ per dollar in 2020, and many times trigger a strong exchange guarantee. The Hong Kong dollar's exchange rate is not only stable but also stronger for the dollar. From April to the end of 2020, there is a net inflow of more than $\$ 50$ billion into the Hong Kong dollar system. Then, in the capital markets, the Hang Seng index fell 3.4\% in 2020. But, in the course of Sino-US trade frictions, the impact of the epidemic and the interference of Western forces, Hong Kong's capital market as a whole remained stable and showed strong resilience. Hong Kong's stock exchange raised HK $\$ 394.246$ billion in the IPO market in 2020, up 26\% from 2019, a little less than NASDAQ, second in the world ${ }^{[8]}$.

From this point of view, Hong Kong's own strength is still very strong, compared with last year's slightly disadvantaged and shown to be "marginalized ", after a short-term recovery, Hong Kong's finance can quickly restore prosperity, not marginalized. So Hong Kong's competitive advantage is still very obvious, marginalization, a little exaggerated.

\section{Conclusions}

For Hong Kong, "marginalization" is unreasonable in general, and Hong Kong's marginalization should be limited in scope. But even if Hong Kong is temporarily at a slight disadvantage in the high-level competition in international financial centers, especially under the influence of the new crown epidemic and anti-regime events, Hong Kong's economy is indeed traumatized, but at the same time, Hong Kong's financial heritage maintained for many years is irreplaceable and short-lived. Even if Hong Kong's rise is partly due to historical helplessness, history has made Hong Kong unique in the world.

In the process of reform and opening up in the new era, Hong Kong has a special position and unique advantages, and plays an irreplaceable role. Hong Kong should think deeply about the strategy and system of "one country, two systems ", believe in the strategic intention of the country and adjust its mentality in time, and have a positive attitude towards the evaluation and prospect of "one country, two systems “. Hong Kong and the mainland should face the problems in the reform of the new era, define its own position and understand the rational decision of the country, and the sense of crisis can help Hong Kong to carry out the correct transformation strategy to some extent.

\section{References}

[1] Daniel Vukovick. The Media Tide Behind the Noise and Fury —_ Revelation of Hong Kong's Anti-examinations in 2019 Economic Guide 2020(07):63-67.

[2] Ji Shuo-ming. A technical recession [N] The development of Hong Kong First Financial Daily, 201911-14(A11).

[3] Ma Li, Guo Baili. Hong Kong's Financial Market Outlook [J] under the Dual Crisis Enterprise Reform and Management 2021(01):99-100.

[4] Global Financial Centre Index Report: China's Top Ten Financial Centres. 4 Chief accountant, China ,2021(03):16.

[5] Wang Ruijiao. A Study on the Construction of China's Financial Center Based on. Geography Northern Economic and Trade Section 2021(03):119-121.

[6] Wang Xiaoya. From the International Financial Centre to the Global Financial Centre [J]; and China Finance, 2021(02):67-69.

[7] Zong Liang, Chang Yunheng, Liu Jin Han. Prospect of Change in the Pattern of International Financial Center [ J].China Finance, 2021 (01): 84 - 86.

[8] Zheng Liansheng. Flexibility [N] in Hong Kong Financial Market Economic Daily ,2021-03-28(010). 